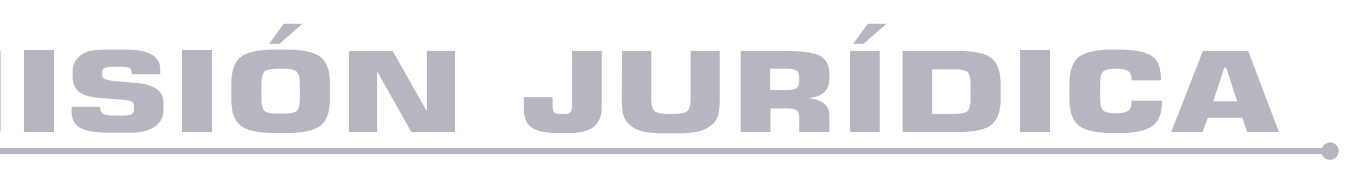

\title{
Retos de una política pública Ecoambiental con enfoque ODS en Bogotá vs Las cláusulas de reversión en servicios de Aseo
}

Challenges of an eco-environmental public policy with an SDG approach versus the reversal clauses in public cleaning services

Autores: Santos Alirio Rodríguez Sierra, Magda Johana Córdoba Cuaran DOI: https://doi.org/10.25058/1794600X.1051

\footnotetext{
Ś MISIÓN JURÍDICA A
} 


\title{
RETOS DE UNA POLÍTICA PÚBLICA ECOAMBIENTAL CON ENFOQUE ODS EN BOGOTÁ VS LAS CLÁUSULAS DE REVERSIÓN EN SERVICIOS DE ASEO*
}

\author{
Challenges of an eco-environmental public policy \\ with an SDG approach versus the reversal clauses \\ in public cleaning services
}

\section{Desafios de uma política pública eco ambiental com uma abordagem dos ODS em Bogotá cláusulas de reversão nos serviços de saneamento}

Santos Alirio Rodríguez Sierra ${ }^{a}$ santoalirioabogados@gmail.com

Magda Johana Córdoba Cuaran ${ }^{\text {b }}$ magdacorc12@gmail.com

Fecha de recepción: 23 de agosto de 2018 Fecha de revisión: 05 de septiembre de 2018 Fecha de aceptación: 10 de dicirmbre de 2018

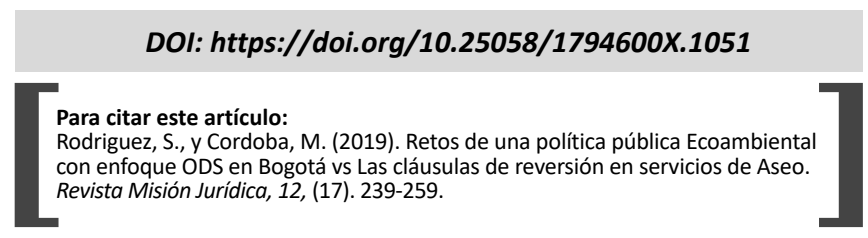

\section{RESUMEN}

El siguiente artículo presenta de manera analítica y crítica el resultado de la investigación sobre: i) La construcción de una Política Pública Ecoambiental en Bogotá (2012-2018), para ello, se analizará el plan de desarrollo de la capital colombiana y la situación ambiental actual de acuerdo con las estrategias de intervención implementadas (manejo de agua, aprovechamiento integral de residuos orgánicos y sólidos, y una educación ambiental de acción). ii) Las condiciones del derecho nacional comparado frente a la importancia de la cláusula de reversión en concesiones de servicios públicos de aseo, iii) Las declaratorias de emergencias sanitarias y la proyección de desmontar los vertederos de residuos sólidos a cielo abierto, cuyos retos debe enfrentar Colombia para cumplir con los Objetivos de Desarrollo Sostenible (ODS).

\footnotetext{
* Trabajo de Investigación elaborado por los estudiantes de la maestría en derecho Administrativo U. Libre.

a. Abogado especializado en Derecho Administrativo, Contractual, Ambiental, Gerencia Pública y Control Fiscal, Maestrías en Gobierno Municipal y Derecho Contencioso Administrativo. Profesor Universitario. Autor de Libros "El Control Fiscal en el derecho comparado" " "El contrato de alquiler de útero materno". Conjuez del Tribunal Contencioso Administrativo de Cundinamarca, del Consejo Superior de la Judicatura CSJ y del Consejo de Estado.
}

b. Abogada de la Universidad del Cauca, especialista en Derecho administrativo, candidata a Magister en Derecho Administrativo de la Universidad Libre. 


\section{PALABRAS CLAVE}

Objetivos de Desarrollo Sostenible; Política pública Ecoambiental; Resiliencia; cláusula de reversión; servicios de aseo; Vertederos a cielo abierto.

\begin{abstract}
This research presents in an analytical and critical way the results of an investigation on: i) The construction of an eco-environmental public policy in Bogotá (2012-2018), to do this, the Colombian capital city's development plan will be analysed as well as the current environmental situation according to the implemented intervention strategies (water management, utilization and integral management of organic and solid wastes, environmental education). ii) The conditions of the national law compared against the importance of the reversal clauses in concessions of public cleaning services, iii) The declarations of sanitary emergencies and the projection of removing the open air solid urban waste disposals, Colombia has to face these challenges to comply with the Sustainable Development Goals (SDG).
\end{abstract}

\section{KEY WORDS}

Sustainable Development Goals, eco-environmental public policy, resilience, reversal clause, public cleaning services, open air waste disposals.

\section{RESUMO}

0 artigo a seguir apresenta de forma analítica e crítica o resultado da pesquisa sobre: (i) A construção de uma Política Pública Ecológica Ambiental em Bogotá (2012-2018), para isso, será analisada o plano de desenvolvimento da capital colombiana e a situação ambiental atual de acordo com as estratégias de intervenção implantada (gestão da água, utilização e gestão integral de resíduos orgânicos e sólidos, educação ambiental). (ii) As condições do direito nacional em comparação com a importância da cláusula de reversão nas concessões de serviços públicos de saneamento, (iii) as declarações de emergências sanitárias e a projeção de desmantelamento dos lixões a céu aberto, cujos desafios devem ser enfrentados Colômbia para cumprir os Objetivos de Desenvolvimento Sustentável (ODS).

\section{PALAVRAS CHAVE}

Objetivos de desenvolvimento sustentável; Política pública ecológica; resiliência; cláusula de reversão; serviços de limpeza; lixeiras a céu aberto.

\section{INTRODUCCIÓN}

El panorama que viven las ciudades "metrópoli", lleva a que los altos índices de población concentrada resten eficacia a cualquier programa de clasificación de residuos para su tratamiento, pues no existe diferenciación entre los de tipo residencial, industrial y comercial, sumado a esto que en la mayoría de los casos los compactadores son ineficientes al igual que las zonas de almacenamiento. Al no existir una política pública con enfoque de Objetivos de Desarrollo Sostenible, que lleve a la transición de vertederos a plantas y centrales de generación eléctrica y a gas, a partir de residuos, seguirá el mismo impacto negativo al medio ambiente sin generar conciencia de sostenibilidad, resiliencia y dignidad por la naturaleza.

Adicional a esta situación, el proceso de investigación deja entrever cómo las organizaciones del sector privado "operadores", no tienen en sus fines el manejo y recuperación del Hábitat, solo preocupándose por acceder a las concesiones a largo tiempo, además de no tener la visión para cambiar sus modos de operación, ya fuere en la modalidad de recolección, disposición y operación a cielo abierto de vertederos para residuos contaminantes.

\section{LECTURA DE UNA POLÍTICA ECOAMBIENTAL BAJO DECLARATORIAS DE EMERGENCIAS EN BOGOTÁ -2012-2018-}

El plan de desarrollo "Bogotá Mejor Para Todos 2016-2020" tiene como objetivo aprovechar el pleno potencial de los habitantes de la capital y reorientar el desarrollo de la ciudad. Este se encuentra estructurado en tres pilares y cuatro ejes trasversales: Los tres pilares construidos para alcanzar el objetivo central del plan y los ejes como requisitos institucionales. La prioridad del plan es atender a la población vulnerable y evitar la intervención pública, permitiendo una construcción a través de la interacción con los habitantes (Peñalosa Londoño, 2016). 
El Pilar 1 hace mención a la búsqueda de igualdad y la inclusión social por medio de programas orientados a la población vulnerable, especialmente a la primera infancia. La ciudad de Bogotá contempla muchas oportunidades a las personas, sin importar su condición sexual social u origen. De esta manera, los diferentes programas se enfocan en la entrega de elementos que ayuden a la población a desarrollar su proyecto de vida por medio de iniciativas educativas, laborales, atención en salud, recreación, deporte y cultura (Peñalosa Londoño, 2016). El Pilar 2, denominado Democracia Urbana, permite incrementar el espacio público, el espacio peatonal y la infraestructura pública por medio de programas orientados al principio constitucional de igualdad, de esta manera, se busca el libre acceso a espacios públicos sin importar su orientación sexual diversidad cultural y capacidades (Peñalosa Londoño, 2016). Finalmente, el Pilar 3, Construcción de Comunidad, tiene como objetivo la consolidación de espacios seguros y confiables para la comunidad donde las víctimas del conflicto sean atendidas y superen su condición de vulnerabilidad, enfocándose en programas de contrucción de paz y prevención de violencia contra las mujeres. Estas actividades permiten el fortalecimiento de los sistemas distritales de derechos humanos, justicia, protección integral a la mujer, y prevención y control del delito. (Peñalosa Londoño, 2016).

En cuanto a los ejes, el primero titulado Nuevo Ordenamiento Territorial, está orientado a implementar en la ciudad instrumentos $\mathrm{y}$ recursos necesarios para la construcción colectiva de la normatividad urbanística, permitiendo la regulación del desarrollo y crecimiento de la ciudad construida, incorporando los principios de democracia urbana. El nuevo ordenamiento es urgente para Bogotá, teniendo en cuenta la creciente población, donde se evidencia la necesidad de establecer políticas para la movilidad regional y la planeación integral del transporte (Peñalosa Londoño, 2016).

El eje transversal 2, Desarrollo Económico Basado en el Conocimiento, promueve las condiciones para que los negocios profundicen la interacción con las instituciones públicas del orden distrital, la comunidad académica y el sector productivo. Los programas para este eje se enfocan en las condiciones de mejora en la calidad de vida urbana para cualquier ámbito del conocimiento (Peñalosa Londoño, 2016).

El eje transversal 3, sobre Sostenibilidad Ambiental Basada en la Eficiencia Energética, se encarga de diseñar una ciudad compacta, con lugares adecuados, minimizado el consumo de energía. Desarrolla estrategias para la recuperación de la Estructura Ecológica, la calidad ambiental, adaptación al cambio climático, reducción de emisiones de $\mathrm{CO} 2$, aprovechamiento de los residuos peligrosos y residuos de construcción. Finalmente, el Eje transversal 4, Gobierno Legítimo y Eficiente, establece condiciones para el buen uso del gobierno distrital, enfocado al servicio ciudadano, busca la modernización institucional a travès de herramientas digitales para la construcción de la ciudad (Peñalosa Londoño, 2016).

\section{Situación ambiental actual y estrategias de intervención en el tratamiento de residuos}

Diferentes son los escenarios que configuran una situación delicada en temas ambientales. Uno de ellos, relacionado con las cerca de 400 empresas registradas cuyo impacto ambiental está asociado a incrementos en la generación de residuos, emisiones, vertimientos y consumo de los recursos naturales, además de deterioro del agua, del suelo y la biodiversidad. Así mismo a nivel local, regional, y global, el cambio climático es preocupante, por la producción gases de efecto invernadero y la quema de combustibles fósiles.

Bogotá es una de las ciudades que ha aportado y apoyado iniciativas y proyectos para la reducción de la emisión de $\mathrm{CO} 2$ de diferentes sectores productivos, igualmente ha implementado diferentes estrategias para mitigar los efectos nocivos de la contaminación. A continuación, se presenta brevemente cada una de las estrategias bandera que han sido implementadas.

El programa de ambiente sano para la equidad y disfrute del ciudadano, el cual busca que se pueda mejorar la calidad del aire, agua y suelo, permitiendo generar un impacto positivo que mejore la calidad de vida. Entre uno de los proyectos se encuentra la modernización de Transmilenio, que por pertenecer al sistema de transporte sostenible incide directamente 
en la calidad ambiental de la ciudad. (Peñalosa Londoño, 2016).

Con respecto al Manejo del agua donde la prioridad es garantizar la disponibilidad, gestión sostenible y el saneamiento para todos, para esto se han implementado desde Planeación Distrital proyectos estratégicos como la descontaminación del Río Bogotá y la purificación del agua potable con el fin de mejorar la calidad de esta. (Peñalosa Londoño, 2016).

En cuanto al aseo, otro ítem importante es la Educación Ambiental, en la cual, las estrategias contemplan proyectos ambientales universitarios, procesos ciudadanos de educación ambiental, formación a dinamizadores ambientales, aulas ambientales, caminatas ecológicas y proyectos ambientales escolares (Alcaldia Mayor de Bogotá, 2018).

Los Proyectos Ambientales Universitarios (PRAU) contemplan la inclusión de la dimensión ambiental en la educación superior, a través de programas de formación, especialización profesional, proyectos de investigación en ambiente y educación ambiental. (Alcaldia Mayor de Bogotá, 2018). El sistema educativo debe tener en cuenta lo siguiente: interdisciplinariedad, transversalidad y cooperación. El trabajo interno de inclusión en la educación ambiental para las entidades de educación superior deberá tener en cuenta la formación investigativa, la formación integral de estudiantes, formación continua de docentes, y la cátedra de educación para la sostenibilidad. (Alcaldia Mayor de Bogotá, 2018)

De otra parte, un aspecto a considerar es la Etnoeducación, entendiendo que de acuerdo con el artículo 7 de la Constitución Política el cual menciona que: "El Estado reconoce y protege la diversidad étnica y cultural de la nación colombiana". La Secretaria de Educación -SED- a través de la pregunta ¿cómo se pueden sistematizar las experiencias, socializarlas y fortalecerlas?; promueve la reflexión frente a los mecanismos y estrategias en las Instituciones Educativas -IED, en las cuales se evidencia un proceso de producción de documentos pedagógicos los cuales retroalimentan y generan desarrollo de futuras acciones ambientales. (Alcaldia Mayor de Bogotá, 2018).

También se evidencian los diferentes procesos comunitarios, los cuales vienen desarrollando estrategias en educación ambiental, con el ánimo de construir el reconocimiento de las potencialidades ambientales en Bogotá. (Alcaldia Mayor de Bogotá., 2018). En la parte de dimensión ambiental, la escuela requiere compromiso y participación de toda su comunidad para que el Proyecto Ambiental Escolar (PRAE) genere aportes al reconocimiento y transformación de los contextos de cada educación distrital (Alcaldia Mayor de Bogotá, 2018).

Hasta aquí, se percibe cómo las entidades del orden distrital tienen diferentes enfoques frente a la problemática generada por los factores contaminantes, y cómo en el aula a través del uso de las artes y el teatro como herramientas pedagógicas, se procura crear conciencia con el medio ambiente realizando actividades que se integran al calendario académico. De esta manera se busca generar una reflexión acerca de que la contaminación se produce las 24 horas del día y que está en nuestras manos disminuirla.

Con respecto al aprovechamiento de los Residuos Orgánicos, este representa beneficios, además de que permite disminuir la problemática que viven las poblaciones cercanas al relleno sanitario, que son las más afectadas. Los abonos orgánicos son importantes para la agricultura porque permiten elevar la producción del suelo, actuando como potenciadores brindando una gran cantidad de nutrientes, es por esto que la utilización de abonos orgánicos permite un mejor aprovechamiento del suelo (Alcaldía de Bogotá y Secretaria Distrital de Hábitat)

Los residuos orgánicos, en los cuales encontramos restos vegetales $\mathrm{y}$ alimenticios, sobrantes de cosecha, aserrines, líquidos biodegradables, madera, etc.; se descomponen por efectos del medio ambiente transformándose en materia orgánica nuevamente. La separación de los residuos se caracteriza dependiendo del uso, actualmente se clasifican en dos categorías: reciclables (residuos de papel, vidrio, metal, bolsas plásticas, cartón, etc.) y orgánicos o biodegradables. (Alcaldía de Bogotá y Secretaria Distrital de Hábitat)

En el proceso de degradación del compostaje se encuentran 3 fases, fase 1 mesófila, que es donde el material comienza un proceso de compostaje a una temperatura ambiente específica, esto se da debido a la actividad microbiana donde los 
microrganismos utilizan fuentes sencillas de carbono y nitrógeno, generando de esta forma calor. También se le asigna el nombre de fase de higienización puesto que el calor generado en los residuos, permite la destrucción de las bacterias. Luego, en la segunda fase denominada enfriamiento continúa la degradación de polímeros, generando hongos visibles. Y, por último, en la fase 3 maduración, la cual conlleva un proceso expenso, produce reacciones secundarias de condensación de compuestos. (Alcaldía de Bogotá y Secretaria Distrital de Hábitat)

Un aspecto clave en el Manejo Integral de Residuos Sólidos, es la instalación de contenedores en donde los residuos depositados puedan ser intervenidos por los recicladores. Adicionalmente en el estudio piloto se ubican canecas en conjuntos residenciales para realizar la separación de materiales reciclables, logrando de esta manera el aprovechamiento a través de la oportuna entrega de las basuras separadas por la comunidad. El paso final de esta operación (embalaje de materiales) se realiza en el Centro de Acopio de la Alquería. (Agencia de Cooperación Internacional del Japón (JICA) y Unidad Administrativa Especial de Servicios Públicos (UAESP), 2013.

Es importante conocer que el relleno sanitario empieza a funcionar desde el año 1988, el cual recibe residuos sólidos domiciliarios y comerciales de Bogotá, mensualmente dispone aproximadamente de 190.000 toneladas, diariamente serían unas 6.400 toneladas. (Agencia de Cooperación Internacional del Japón (JICA) y Unidad Administrativa Especial de Servicios Públicos (UAESP), 2013)

Las instalaciones del relleno cuentan con acceso, dos básculas de pesaje para llevar un respectivo control de ingreso, vías de acceso en suelos granulares, estación meteorológica, pondajes, plantas de aprovechamiento, celdas de residuos hospitalarios, etc. (Agencia de Cooperación Internacional del Japón (JICA) y Unidad Administrativa Especial de Servicios Públicos (UAESP), 2013)

Sobre la vida útil del relleno, se tiene en cuenta el volumen remanente y las proyecciones de residuos a considerar, el relleno tiene 21,4 años de vida útil más o menos hasta el 2033. (Agencia de Cooperación Internacional del Japón (JICA) y Unidad Administrativa Especial de Servicios Públicos (UAESP), 2013).

Teniendo en cuenta el Plan Maestro, el Distrito Capital, se adelanta un Plan de Manejo Integral de Residuos Sólidos (PMIRS), a fin de implementar un nuevo sistema de disposición de residuos sólidos enfocados al reciclaje de materiales y volúmenes de residuos. (Agencia de Cooperación Internacional del Japón (JICA) y Unidad Administrativa Especial de Servicios Públicos (UAESP), 2013).

En las nuevas políticas (estrategias de producción sostenible, modelos de reciclaje, aprovechamiento final, minimización de la disposición del relleno sanitario y gestión integral de residuos especiales y peligrosos) se incluye a Basura Cero, enmarcada en el Plan de Desarrollo. (Agencia de Cooperación Internacional del Japón (JICA) y Unidad Administrativa Especial de Servicios Públicos (UAESP), 2013).

Según el Plan Maestro, se promoverá el reciclaje a través de recolección selectiva de residuos, compostaje de residuos orgánicos provenientes generalmente de las Plazas de mercado, el corte del césped y el reciclaje de escombros; también pretenden implementar 2 rellenos sanitarios más, ubicados al norte de la ciudad y al occidente. (Agencia de Cooperación Internacional del Japón (JICA) y Unidad Administrativa Especial de Servicios Públicos (UAESP), 2013).

\section{ANÁLISIS DE LA PROBLEMÁTICA DEL DERECHO NACIONAL Y COMPARADO FRENTE A LA IMPORTANCIA DE LA CLÁUSULA DE REVERSIÓN EN CONCESIONES DE SERVICIOS PÚBLICOS DE ASEO}

Los ODS, vienen a nivel regional dando una lucha por ser insertos en las estrategias locales, para el caso "...La Secretaria Ejecutiva de la CEPAL remarcó que la Agenda 2030 requiere de un nuevo multilateralismo que fortalezca la confianza en la cooperación internacional y la acción colectiva para la provisión de bienes públicos globales y regionales, que aumente la resiliencia ante los choques financieros, comerciales y tecnológicos, que universalice estados de bienestar y proteja los derechos de las minorías, que fortalezca los intereses difusos de la mayoría por sobre los intereses de grupos organizados o que concentran capital y tecnología, y que fortalezca las capacidades deliberativas, la transparencia 
y el debate informado del conjunto de los ciudadanos..." Cepal (2018)

Ahora el reto que se propone la cumbre de Lima (2019):

La Cumbre reunirá a los gobiernos, el sector privado, la sociedad civil, las autoridades locales y otras organizaciones internacionales para desarrollar soluciones ambiciosas en seis áreas: una transición global a las energías renovables; Infraestructuras y ciudades sostenibles y resilientes; Agricultura sostenible y manejo de bosques y océanos; resiliencia y adaptación a los impactos climáticos; y alineación de las finanzas públicas y privadas con una economía neta cero. (Recuperado: https://www.un.org/en/ climatechange/un-climate-summit-2019.shtml )

Unas regiones como Panamá - publicación de la gaceta digital oficial № 25821 del martes 26 de junio de 2017-, vienen diseñando en sus modelos de contratos, de manera explicita en su clausulado, la finalidad y operancia de la reversión, y de esta manera suple los vacíos que la legislación colombiana aún persiste.

(...) Que la Resolución A/RES/64/292, de la Asamblea General de la Naciones Unidas, proclama en su sesión plenaria del 28 de julio de 2010, lo siguiente:

- "Reconoce que el derecho al agua potable y el saneamiento es un derecho humano esencial para el pleno disfrute de la vida y de todos los derechos humanos;

- Exhorta a los Estados y las organizaciones internacionales a que proporcionen recursos financieros y propicien el aumento de la capacidad y la transferencia de tecnología por medio de la asistencia y la cooperación internacionales, en particular a los países en desarrollo, a fin de intensificar los esfuerzos por proporcionar a toda la población un acceso económico al agua potable y el saneamiento;

- Acoge con beneplácito la decisión del Consejo de Derechos Humanos de pedir a la experta independiente sobre las obligaciones de derechos humanos relacionadas con el acceso al agua potable y el saneamiento que presente un informe anual a la Asamblea General, y alienta a la experta independiente a que siga trabajando en todos los aspectos de su mandato y a que, en consulta con todos los organismos, fondos y programas pertinentes de las Naciones Unidas, incluya en el informe que le presente en su sexagésimo sexto período de sesiones las principales dificultades relacionadas con el ejercicio del derecho humano al agua potable y el saneamiento y su efecto en la consecución de los objetivos de Desarrollo del Milenio".

\section{En el ámbito nacional}

En el ámbito de la investigación se tiene que la reglamentación deja unos vacíos que incluso los servicios públicos deben someterse a la Constitución y también a una determinación previa y especifica del legislador (C.P. art. 367, 369 y 370), en los términos de las normas antes reseñadas, debe permanecer en concordancia con el marco normativo de las cuestiones básicas que estructuran la naturaleza propia de cada servicio, sus atributos de regularidad, permanencia eficacia y eficiencia, los sujetos que los prestan, las relaciones usuarioentidad prestataria, la manera de establecer las tarifas que se pagan y los subsidios que demanda la universalidad y solidaridad del servicio, el contenido y alcance del control, inspección y vigilancia, atribuido a la Superintendencia de Servicios Públicos, y la financiación de esta.

En la naturaleza del contrato, existen unas cláusulas, como la de Reversión, que no se encuentra expresa, pero forman parte del contrato:

...jurídicamente la transferencia de los bienes de la concesión del particular a la entidad estatal se justifica en la medida en que el valor de tales bienes está totalmente amortizado, siempre y cuando se encuentren satisfechos los presupuestos del vencimiento de términos $\mathrm{y}$, además, que ese valor de los bienes que se utilicen para el desarrollo y ejecución del contrato de concesión se paga por la entidad estatal concedente al momento de celebrar el contra de concesión... (Matallana Camacho, 2009, pág. 709).

La cláusula de reversión entonces es una especie de expropiación de bienes sin indemnización alguna. Pero dentro del contrato de concesión, el concesionario debe constituir una fiducia, de hasta el 50\%, para que recaude los recursos de la concesión, y los aportes del Estado destinados exclusivamente para la labor estipulada en dicho contrato. Los contratos de Servicio domiciliario de aseo, no por ser remunerados se consideran 
onerosos, sino de utilidad razonable, además dicha remuneración se encuentra reglamentada por las comisiones de regulación según lo establecido en la Ley 142 de 1994.

La cláusula de reversión es para los contratos de concesión de obra pública y los de explotación, una cláusula obligatoria, mas no para los de áreas exclusivas o servicios públicos domiciliarios de aseo.

El contrato es acto típico entre los que crean situaciones jurídicas de carácter particular. Los contratantes modelan la situación jurídica según su voluntad. Crean derechos y obligaciones. Pero el acuerdo de voluntades para que sea válido debe producirse dentro del marco de la ley que señala la capacidad y competencia de los contratantes, los procedimientos y formas del acuerdo y los fines que pueden constituir su objeto lícito. En este sentido puede decirse que la ley vigente al momento de contratar se incorpora al contrato en cuanto determina la validez formal e intrínseca de las obligaciones y derechos de los contratantes. (Ley 153/87, art. 38).

Así las cosas, al hacer un análisis jurisprudencial del Consejo de Estado y de la Corte Constitucional, así como la doctrina en el asunto de los contratos de concesión, se concluye:

- La Ley 80 de 1993 establece como modalidades de contrato de concesión los que se realizan para la prestación, operación, explotación, organización o gestión total o parcial de un servicio público.

- Que la reversión es un elemento de la esencia del contrato de concesión que se entiende unido así las partes no lo hubiesen señalado expresamente.

- Son objeto de reversión todos aquellos bienes y demás elementos que se encuentren directamente afectos a la concesión o explotación de bienes estatales.

- Siempre que se entreguen bienes estatales para su explotación bajo la modalidad de concesión, las partes deberán pactar la cláusula de reversión.

El problema jurídico de la investigación radica en la defensa de dicha competencia y la posición dominante que poseen las empresas privadas prestadoras de servicios públicos, en este caso domiciliario de aseo, al devolver al Estado todos los bienes que ella adquirió bajo la libre competencia otorgada por la ley, incurriendo en violación del artículo 30 de la misma: "Principios de interpretación. Las normas que esta ley contiene sobre contratos se interpretarán de acuerdo con los principios que contiene el título preliminar; en la forma que mejor garantice la libre competencia y que mejor impida los abusos de la posición dominante, tal como ordena el artículo 333 de la Constitución Política; y que más favorezca la continuidad y calidad en la prestación de los servicios." (Art. 30 de la Ley 142 de 1993).

\section{Ley 632 de 2000. Por la cual se modifican parcialmente las leyes 142 , 143 de 195, 223 de 1995 y 286 de 1996.}

En el artículo nueve de esta ley, se establecen los esquemas de prestación de servicio público domiciliario de aseo: recolección y transporte de los residuos ordinarios de grandes generadores, reciclaje, operación comercial, etc., también afirma que los municipios y distritos responsables de asegurar su prestación, pueden aplicar el principio de Libre Competencia y concurrencia de prestadores del servicio, acorde con la norma.

Para las actividades de recolección, transferencia y transporte de residuos generados por usuarios residenciales y pequeños productores, residuos patógenos y peligrosos, y para la limpieza integral de vías, áreas y elementos que componen el amoblamiento urbano público, los municipios y distritos deberán asegurar la prestación del servicio, para lo cual podrán asignar áreas de servicio exclusivo, mediante la celebración de contratos de concesión, previa la realización de licitación pública, procedimiento con el cual se garantizará la competencia." Art. 9 Ley 632 de 2000

El problema de investigación planteado sustenta que el contrato de concesión que se realizó fue para la prestación del servicio público de aseo en municipios y que además de tener una libre competencia, fue pactado como de "zonas exclusivas", en este tipo de contrato la cláusula de reversión sufre unas excepciones, y por ello, las empresas en conflicto se negaron a devolver los recursos o bienes materiales que obtuvieron durante la vigencia del contrato como si fuera patrimonio del Estado. 


\section{Antecedentes del caso sobre el tratamiento de los residuos sólidos a nivel metropolitano}

La Sentencia T-724 de 2003, surgió con unas ordenes puntuales ante la declaratoria de emergencia sanitaria del distrito de Bogotá -2012-, que llevó la expedición de la reglamentación de los planes de manejo de residuos sólidos, que han variado, y complementado año por año (ver cuadro)

Creándose regularizaciones como las previstas en el artículo 212, 213 y sig, del Decreto 190 de 2004 que establece que el Sistema para la Gestión Integral de Residuos Sólidos requiere para su operación adecuada de los siguientes equipamientos e infraestructuras por tipo de proceso y por tipo de residuo:

Tabla 1

Equipamientos e infraestructuras

\begin{tabular}{|c|c|c|}
\hline TIPO DE PROCESO & TIPO DE RESIDUOS & EQUIPAMIENTOS \\
\hline \multirow{3}{*}{$\begin{array}{l}\text { Prevención, reciclaje y } \\
\text { aprovechamiento }\end{array}$} & \multirow{3}{*}{ Ordinarios } & Centros de reciclaje \\
\hline & & Bodegas especializadas \\
\hline & & Centros de acopio \\
\hline \multirow{4}{*}{ Recolección y Transporte } & Hospitalarios & Bases de operación \\
\hline & Peligrosos & Bases de operación \\
\hline & Escombros & Bases de operación \\
\hline & Residuos ordinarios & Bases de operación \\
\hline Transferencia & Residuos ordinarios & Estaciones de transferencia \\
\hline \multirow{6}{*}{ Tratamiento } & Hospitalarios & \\
\hline & & Plantas de desactivación \\
\hline & Peligrosos & Unidad de estabilización fisicoquímica \\
\hline & Escombros & PlantadetrituraciónoCentrosdeAprovechamiento \\
\hline & Orgánicos & Planta de compostaje \\
\hline & Lixiviados & Planta \\
\hline \multirow{5}{*}{ Disposición final } & \multirow{2}{*}{ Ordinarios } & Optimización Relleno \\
\hline & & Construcción nuevo relleno \\
\hline & Escombros & Escombreras \\
\hline & Biosólidos & Rellenos controlados \\
\hline & Peligrosos & Celda de seguridad \\
\hline
\end{tabular}

Fuente: Creación Propia, basada en la normatividad emitida en RS para el Distrito Capital de Bogotá.

\section{Los autos de la Corte Constitucional 268/2010, 275/2011, 084/2012, $366 / 2014 b, 089 / 2015$}

Tenemos una normatividad desactualizada que data de hace cuatro décadas como es el Decreto 2811 de 1974 (Código Nacional de Recursos Naturales Renovables y de Protección al Medio Ambiente), en el Titulo III, Artículo $\underline{34}$, establece que para el manejo de los residuos sólidos, basuras, desecho y desperdicios, se utilizarán los mejores métodos, de acuerdo con los avances de la ciencia y la tecnología, para la recolección, tratamiento, procesamiento o disposición final de residuos, basuras, desperdicios $y$, en general, de desechos de cualquier clase.

El mencionado decreto señala en su Artículo $\underline{36}$ que para la disposición o procesamiento final de 
las basuras se utilizarán, preferiblemente, los medios que permitan: a-. Evitar el deterioro del ambiente y de la salud humana; b-. Reutilizar sus componentes; c-. Producir nuevos bienes; d-. Restaurar o mejorar los suelos

La Corte Constitucional mediante Auto 275 de 2011, resaltó la importancia de la participación de los recicladores en la formulación del PGIRS como una norma determinante en el ámbito local a fin de "(...) consolidar su accionar económico y mejorar su calidad de vida. Adicionalmente, a nivel constitucional, las medidas que sean adoptadas, además de perseguir un objetivo legítimo, ser eficaces y temporales, deben incidir en la solución de las situaciones de discriminación que padecen determinados grupos concretos y cumplir con la proporcionalidad y racionalidad que de ellas se predica. (...) “

En el auto en cita la Corte ordenó "que el Distrito defina y rediseñe un esquema que dignifique la actividad del reciclaje y que tienda a su normalización a través de la fijación de metas a cumplir en el corto plazo que sean concretas, cualificadas, medibles y verificables. Tal esquema será entregado a esta Corte (...) El esquema que contenga las mencionadas acciones positivas en favor de los recicladores se podrán incluir a nivel de regulación distrital, en el plan de gestión integral de residuos sólidos -PGIRS-, siempre que su ejecución se materialice en el corto plazo, en los procesos de concesión y/o contratación de servicios de aseo, así como en la prestación misma de los mencionados servicios públicos, de acuerdo con las pautas generales y criterios ya señalados por esta Corporación en sus diferentes providencias (en especial la sentencia T-724 de 2003 y el Auto $\underline{268}$ de 2010), la normatividad vigente y la especificidad del componente de aseo.(...) “

Que en las consideraciones hechas por la Corte Constitucional el auto exhorta por el desarrollo un proceso de cambio en los recicladores, que les permita constituirse en prestadores del servicio público de aprovechamiento, organizados en empresas de economía social y comercializando su producto de manera integrada:

"Si se tiene en cuenta que el fin de las acciones afirmativas que se demandan, no es otro que el que la operación del servicio público complementario de aprovechamiento esté en cabeza de sus destinatarios naturales -los recicladores-, este podría ser tenido en principio como una formal acción afirmativa. Sin embargo, la eficacia de la medida radica en que este grupo se encuentre materialmente preparado para asumir la operación del servicio. De lo contrario, este cambio de paradigma no tendría ninguna repercusión desde el punto de vista práctico, pues sin la adecuada organización y logística este grupo marginal seguirá realizando su labor sin que se aprecien cambios significativos ",

En igual finalidad el Auto 275 de 2011 señala que es necesario para el servicio público de aprovechamiento, desarrollar infraestructuras para la operación del mismo, "No existen razonablemente centros de acopio y recepción del material reciclable, cercanos a los sitios de recolección, y los vehículos de tracción humana no son idóneos ni eficaces para el transporte de residuos en trayectos largos, si se tiene en cuenta que muchas áreas no cuentan con centros de reciclaje y los existentes se ubican en zonas que demandan largos desplazamientos".

Ahora el Acuerdo Distrital 287 de 2007 por el cual se establecen lineamientos para aplicar las acciones afirmativas que garantizan la inclusión de los recicladores de oficio en condiciones de pobreza y vulnerabilidad en los procesos de la gestión y manejo integral de los residuos sólidos", establece en el artículo $4^{\circ}$ que las entidades públicas distritales vinculadas a la gestión y manejo de los residuos sólidos adelantarán acciones afirmativas orientadas a establecer mecanismos que permitan condiciones de igualdad real de los recicladores en los procesos contractuales vinculados a la gestión y manejo integral de los residuos sólidos.

Que de conformidad con lo establecido en la Ley $\underline{142}$ de 1994, el Gobierno Nacional expidió el Decreto 2981 de 2013, por el cual se reglamenta la prestación del servicio público de aseo y establece que corresponde a la entidad territorial la formulación, implementación, evaluación, seguimiento y control y actualización del PGIRS. 
Tabla 2

Cuadro normas sobre planes de manejo de residuos solidos

\begin{tabular}{|c|c|c|}
\hline NORMA DISTRITAL & TEMA & AUTORIDAD \\
\hline $\begin{array}{l}\text { Decreto № } 312 \text { de } 2006 \\
\text { http://www.alcaldiabogota. } \\
\text { gov.co/sisjur/normas/Norma1. } \\
\text { jsp?i=21059 }\end{array}$ & Plan Maestro Manejo de residuos Solidos & $\begin{array}{lcr}\text { Unidad } & \text { Ejecutiva } & \text { de } \\
\text { Servicios } & \text { Públicos } & \text { del } \\
\text { Distrito } & \text { Capital } & \text { de } \\
\text { Bogotá } & & \\
\end{array}$ \\
\hline $\begin{array}{l}\text { Decreto } 620 \text { de } 2007 \\
\text { http://www.alcaldiabogota. } \\
\text { gov.co/sisjur/normas/Norma1. } \\
\text { jsp?i=28150 }\end{array}$ & $\begin{array}{l}\text { regularización y construcción de las } \\
\text { infraestructuras y equipamientos del Sistema } \\
\text { General de Residuos Sólidos }\end{array}$ & $\begin{array}{l}\text { Autoridades Distritales } \\
\text {-Secretarias }\end{array}$ \\
\hline $\begin{array}{l}\text { Decreto } 456 \text { de } 2010 \\
\text { http://www.alcaldiabogota. } \\
\text { gov.co/sisjur/normas/Norma1. } \\
\text { jsp?i=40643 }\end{array}$ & Regulación urbanística y zonas de reciclaje & $\begin{array}{l}\text { Autoridades Distritales } \\
\text {-Secretarias } \\
\text { Curadurías }\end{array}$ \\
\hline $\begin{array}{l}\text { Decreto № } 469 \text { de } 2015 \\
\text { http://www.alcaldiabogota. } \\
\text { gov.co/sisjur/normas/Norma1. } \\
\text { jsp?i=63787 }\end{array}$ & $\begin{array}{l}\text { Regulación sobre bodegas de Reciclaje y } \\
\text { otras disposiciones }\end{array}$ & $\begin{array}{l}\text { Autoridades Distritales } \\
\text {-Secretarias }\end{array}$ \\
\hline $\begin{array}{l}\text { Decreto № } 2981 \text { de } 2013 \\
\text { http://www.alcaldiabogota. } \\
\text { gov.co/sisjur/normas/Norma1. } \\
\text { jsp?i=56035\#0 }\end{array}$ & $\begin{array}{l}\text { Por el cual se reglamenta la prestación del } \\
\text { servicio público de aseo }\end{array}$ & $\begin{array}{l}\text { Entidades prestadoras } \\
\text { de Servicios Públicos } \\
\text { de Aseo }\end{array}$ \\
\hline $\begin{array}{l}\text { Decreto № } 113 \text { de } 2013 \\
\text { http://www.bogotajuridicadigital. } \\
\text { gov.co/sisjur/normas/Norma1. } \\
\text { jsp?i=52363 }\end{array}$ & $\begin{array}{l}\text { Adopción de normas urbanísticas y } \\
\text { arquitectónicas para la implantación y } \\
\text { regularización de bodegas privadas de } \\
\text { reciclaje de residuos sólidos no peligrosos no } \\
\text { afectas (Sic) al servicio público de aseo, y se } \\
\text { dictan otras disposiciones }\end{array}$ & $\begin{array}{l}\text { Autoridades Distritales } \\
\text {-Secretarias }\end{array}$ \\
\hline $\begin{array}{l}\text { Decreto } 548 \text { de } 2015 \\
\text { http://www.alcaldiabogota.gov.co/ } \\
\text { sisjur/normas/Norma1.jsp?i=64204 }\end{array}$ & $\begin{array}{l}\text { "Por el cual se adopta el Plan de Gestión } \\
\text { Integral de Residuos Sólidos -PGIRS- del } \\
\text { Distrito Capital,ysedictan otras disposiciones" }\end{array}$ & $\begin{array}{l}\text { Autoridades Distritales } \\
\text {-Secretarias }\end{array}$ \\
\hline
\end{tabular}

Fuente: Creación Propia, basada en la normatividad emitida en RS para el Distrito Capital de Bogotá.

Para el año 2012 inicia el cambio en el sistema de recolección de los RS en la capital que dio comienzo a la instauración del programa del Plan de Desarrollo Distrital "Bogotá Basura Cero", la nueva entidad encargada de la recolección Aguas de Bogotá, filial de la Empresa de Acueducto, Alcantarillado y Aseo de Bogotá (EAB-ESP), está orientado a reducir paulatinamente la generación de residuos sólidos, mediante la adecuada separación en la fuente, el reciclaje, la revalorización y transformación de la mayor cantidad de materiales posibles; lo anterior, en relación con lo estipulado en la sentencia T-724 de 2003 de la Corte Constitucional, en la que se impartió a la Unidad Administrativa Especial de
Servicios Públicos -UAESP- órdenes a efectos de garantizar el desarrollo de acciones afirmativas a favor de la población de recicladores de Bogotá.

Unos gobiernos de turno han declarado la emergencia sanitaria -2012-2018- a fin ajustar y distribuir el gran negocio de la recolección a los operadores privados que había sido retirados de manera transitoria, en el primer caso Basura Cero, le apostó a crear una política de Red Ambiental, ahora se encuentra toda su maquinaria -flotilla compactadores- en condición de depósito inactivo subutilizado, las instalaciones bodega de acueducto de Bogotá sector Sopo- vía Briceño. (Ver Imagen1) 


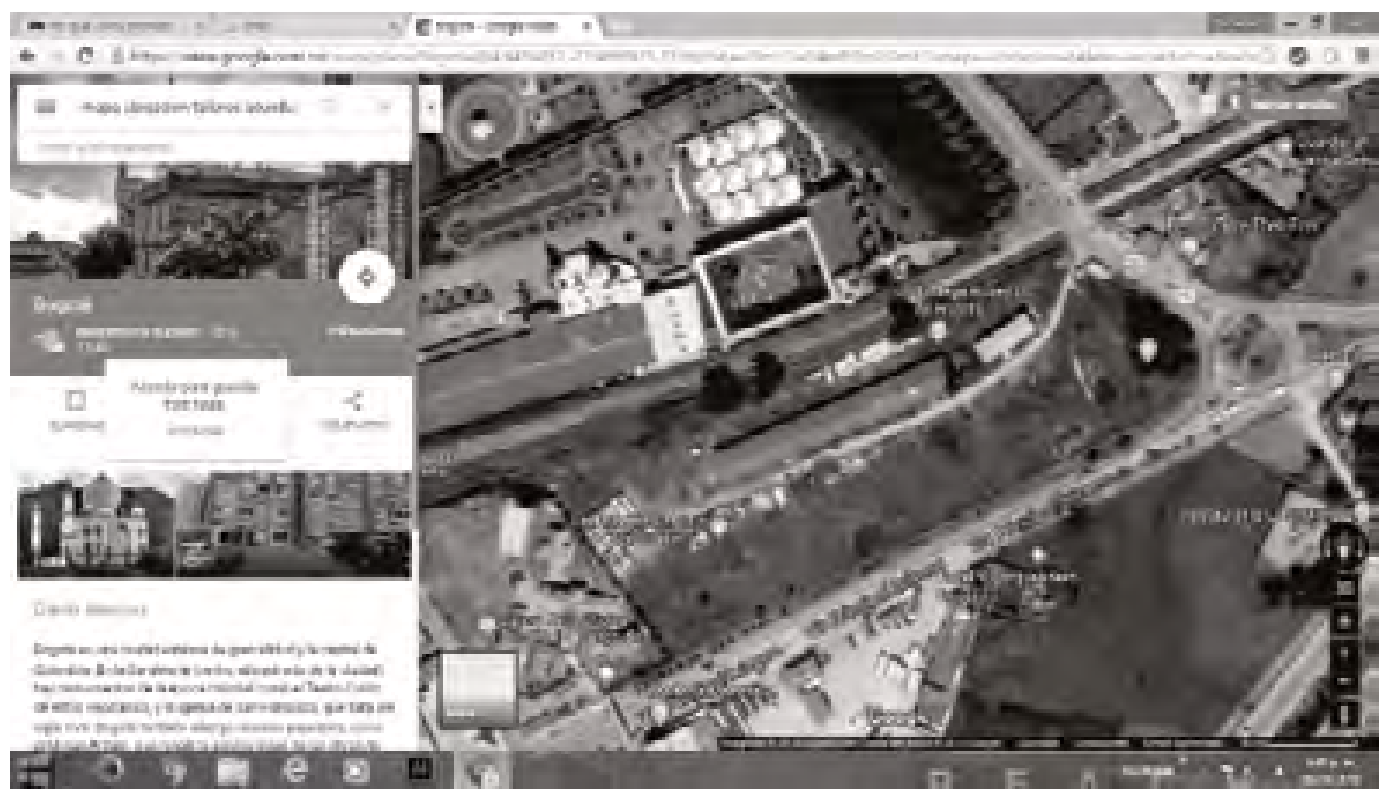

Gráfico 1- ubicación satelital lote bodega acueducto de Bogotá

El otro momento -2018-, ya liquidada la iniciativa del programa "Basura Cero" a pesar de sus resultados (ver Imagen 2), regresó el modelo a los antiguos operadores -ver cuadro- que solo recogen los residuos y lo dejan en el vertedero Doña Juana, atándose al clausulado que les impone deberes limitados, pero no los obliga a dar recursos para un fondo de reposición y cambio del vertedero actual, a otro tipo de tecnología ambiental, ello obedece a la ausencia de una política pública en tal sentido, tal como lo deja claro esta investigación. (Ver Imagen 2)

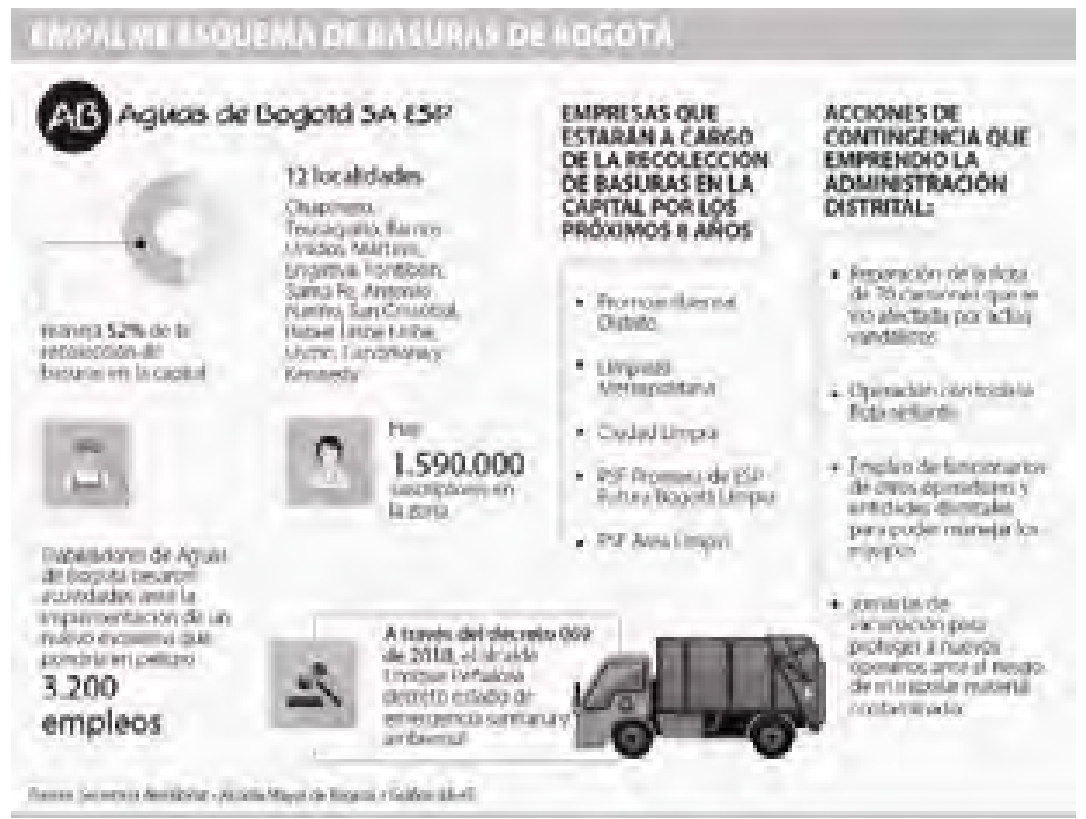

Gráfico 2- Esquema de basuras Bogotá

Fuente, Secretaria de Hábitat-Alcaldía mayor de Bogotá / La república o8 Febrero 2018 recuperado de https://www. larepublica.co/economia/cada-tonelada-de-basura-dispuesta-en-dona-juana-le-cuesta-21545-a-la-ciudad-2597300 


\section{Problemáticas en la transición del sistema RS}

El Distrito ha llevado varias decisiones bajo el paraguas de las declaratorias de emergencia 2012-2018, una para crear un sistema novedoso y otra para luego de una lucha de intereses, regresar el manejo al sector privado-Ver figura 3-, y de esta manera tanto unos como otros, no darle cabida al bienestar de las comunidades y menos de crear una política en beneficio del medio ambiente.

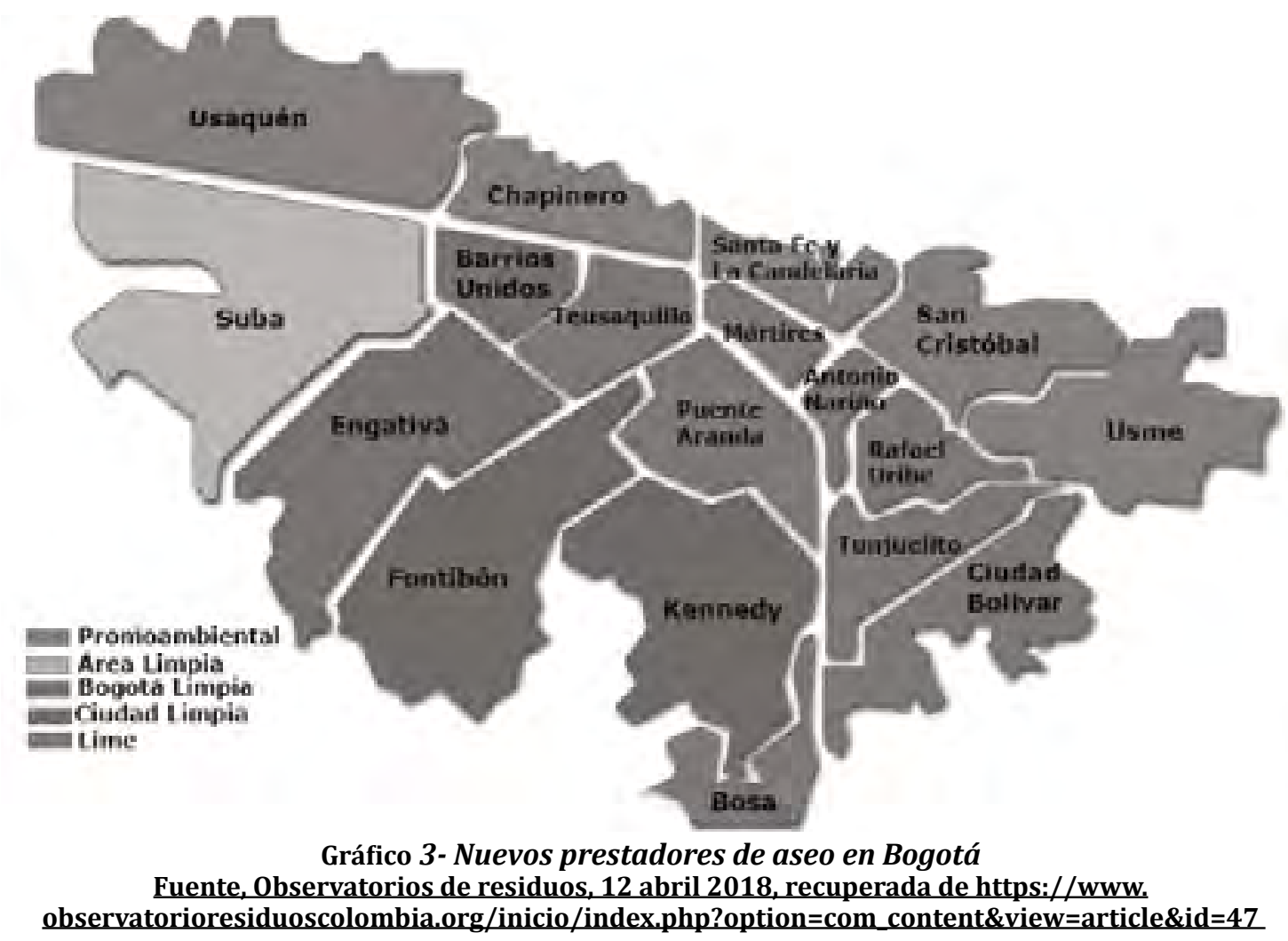

\section{Caracterización de la población recicladora de oficio en Bogotá, analisis de los datos del Censo 2012.}

Los recicladores para el año 2002 interpusieron una tutela, con la cual buscaban conformar una empresa prestadora del servicio de aseo público para la ciudad de Bogotá y de esta forma ser parte de una actividad económica importante. Posteriormente a esta iniciativa lograron crear condiciones de reconocimiento, remuneración y organización empresarial. (Castro B, 2014)

El Plan de Desarrollo en su fase de implementación, la cual fue consedida por la Corte Constitucional mediante el Auto 275 de 2011, soportada en Basura Cero, mediante su articulo
30 del Plan de Desarrollo establecio."Se orienta a minimizar el impacto de los escombros y los residuos sólidos, incluyendo los especiales y peligrosos, generados por la ciudad sobre el ambiente y la salud de la ciudadania". (Castro B, 2014, pág. 10)

Tambien menciona la "cultura de reducción de basuras y separación en la fuente, los modelos de reciclaje para Bogotá, el aprovechamiento final de minimización de la disposición en el relleno sanitario. (Castro B, 2014, pág. 22)

Teniendo en cuenta la base de recicladores ajustada (vr29 de agosto del 2013), se pudo observar la cifra de 13.771 recicladores, la UAESP, mencionó que es posible que algunos recicladores quedaran por fuera del censo realizado. 
Tabla 3

No. recieladores por I.OCAL.IDAD en donde se realizó la entrevista

\begin{tabular}{|c|c|c|c|}
\hline & localidad & $\begin{array}{l}\text { No. recieladores } \\
\text { por LOCALIDAD } \\
\text { en donde se realizó } \\
\text { la entrevista }\end{array}$ & $\%$ \\
\hline 17 & La Candelaria & 8 & 0,1 \\
\hline 13 & Teusaquillo & 49 & 0,4 \\
\hline 15 & Antonio Narino & 74 & 0,5 \\
\hline 2 & Chapinero & 100 & 0,7 \\
\hline 1 & Usaquén & 370 & 2,7 \\
\hline 6 & Tunjuelito & 443 & 3,2 \\
\hline 5 & Usme & 504 & 3,7 \\
\hline 9 & Fontiboin & 524 & 3,8 \\
\hline 4 & San Cristóhal & 546 & 4,0 \\
\hline 12 & Barrios Unidos & 632 & 4,6 \\
\hline 14 & Los Mártines & 718 & 5,2 \\
\hline 16 & Puente Amanda & 755 & 5,5 \\
\hline 3 & Santafe & 766 & 5,6 \\
\hline 18 & Rafael Uribe Uribe & 870 & 6,3 \\
\hline 7 & Bosa & 948 & 6,9 \\
\hline 10 & Engativá & 957 & 6,9 \\
\hline 19 & Ciudad Bolivar & 1348 & 9.8 \\
\hline II & Suba & 1431 & 10.4 \\
\hline 8 & Kennedy & 2728 & 19.8 \\
\hline total & & 13771 & 100 \\
\hline
\end{tabular}

Fuente: UD Base de datos censo de recicladores 2012 Vr 29 agosto 2013

Grafico 4 -Censo de poblacion recicladora en Bogotà

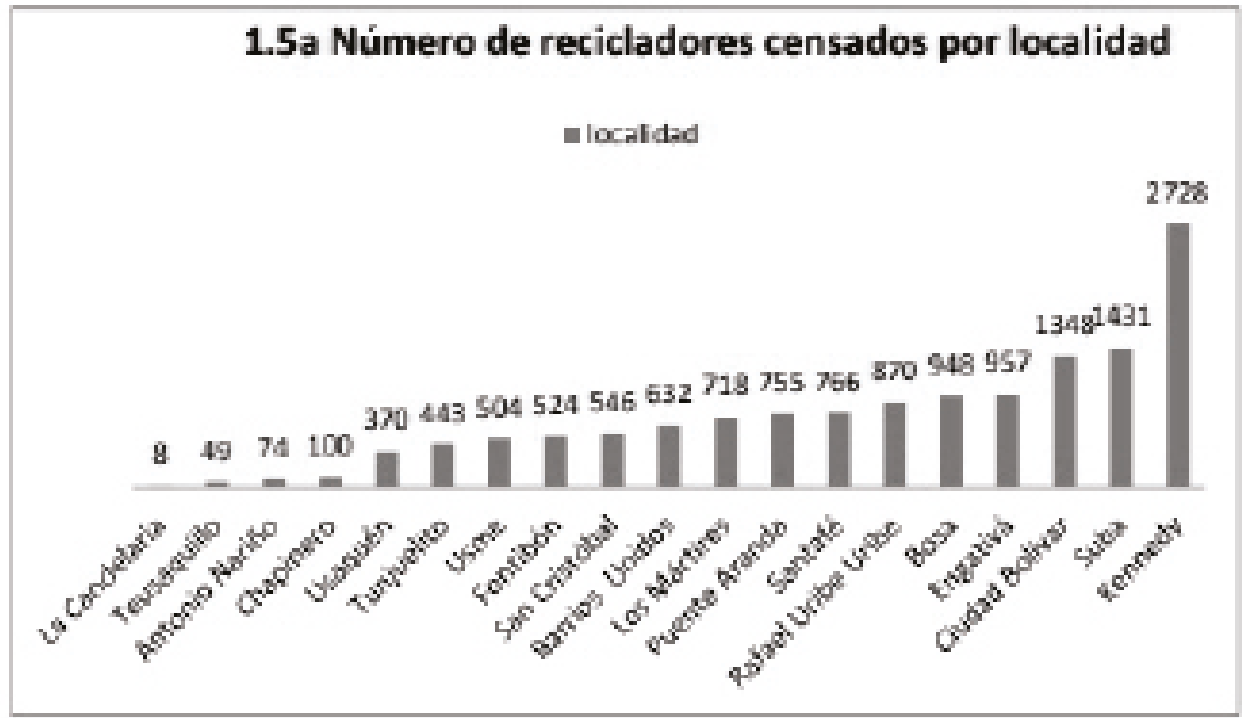

Fuente: UD Base de datos censo de recicladores 2012 Vr 29 agosto 2013 
Se puede observar en la tabla y grafica anterior que la localidad donde mas se encuentran recicladores, teniendo en cuenta el censo, es Kennedy con un 19,8\% y la localidad más baja es la Candelaria con un $0,1 \%$. Los recicladores generalmente acuden a bodegas donde el consumo es mayor para realizar venta del material. (Castro B, 2014)

\section{Documento Técnico de Soporte del Plan de Gestión Integral de Residuos Sólidos PGIRS para Bogotá.}

A continuación, se visualizarán cuadros que permiten identificar la generación de Residuos sólidos.

Tabla 4- Generación de Residuos Sólidos.

\begin{tabular}{|c|c|c|c|c|}
\hline \multirow{8}{*}{ 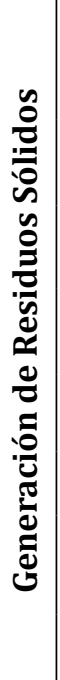 } & \multirow{8}{*}{$\begin{array}{l}\text { Cantidad } \\
\text { de residuos } \\
\text { generados por } \\
\text { actividades del } \\
\text { servicio público } \\
\text { de aseo teniendo } \\
\text { en cuenta la } \\
\text { generación } \\
\text { mensual en área } \\
\text { urbana }\end{array}$} & \multirow{8}{*}{$\begin{array}{l}\text { Ton } \\
\text { /mes }\end{array}$} & Origen & \multirow{2}{*}{$\begin{array}{l}\begin{array}{l}\text { Promedio } \\
\text {-Diciembre de } 2015 \\
\text { Ton-mes }\end{array} \\
149.167,48\end{array}$} \\
\hline & & & $\begin{array}{l}\text { Residuos recogidos domiciliarios (Ton/mes) } \\
\text { RSDJ }\end{array}$ & \\
\hline & & & $\begin{array}{l}\text { Residuos recogidos domiciliarios (Ton/mes) } \\
\text { RSDJ }\end{array}$ & $8.544,55$ \\
\hline & & & $\begin{array}{l}\text { Residuos recogidos de corte césped (ton/mes) } \\
\text { RSDJ }\end{array}$ & $1.622,06$ \\
\hline & & & $\begin{array}{l}\text { Residuos recogidos de grandes generadores } \\
\text { (ton/mes) RSDJ }\end{array}$ & $10.610,45$ \\
\hline & & & Residuos mixtos recogidos (ton/mes) RSDJ & $18.881,75$ \\
\hline & & & $\begin{array}{l}\text { Residuos recogidos de poda Árboles (Ton/mes) } \\
\text { RSDJ }\end{array}$ & 488,08 \\
\hline & & & Total residuos recogidos (Ton/mes) RSDJ & $189.238,94$ \\
\hline
\end{tabular}

Fuente: Interventoría Consorcio Inter Capital Oficio de radicado UAESP: 20166010058912 del 11 de marzo de 2016. Información modificada, respecto del Decreto 548 del 17 de diciembre de 2015. Información aprobada mediante Decreto 227 de 2016.

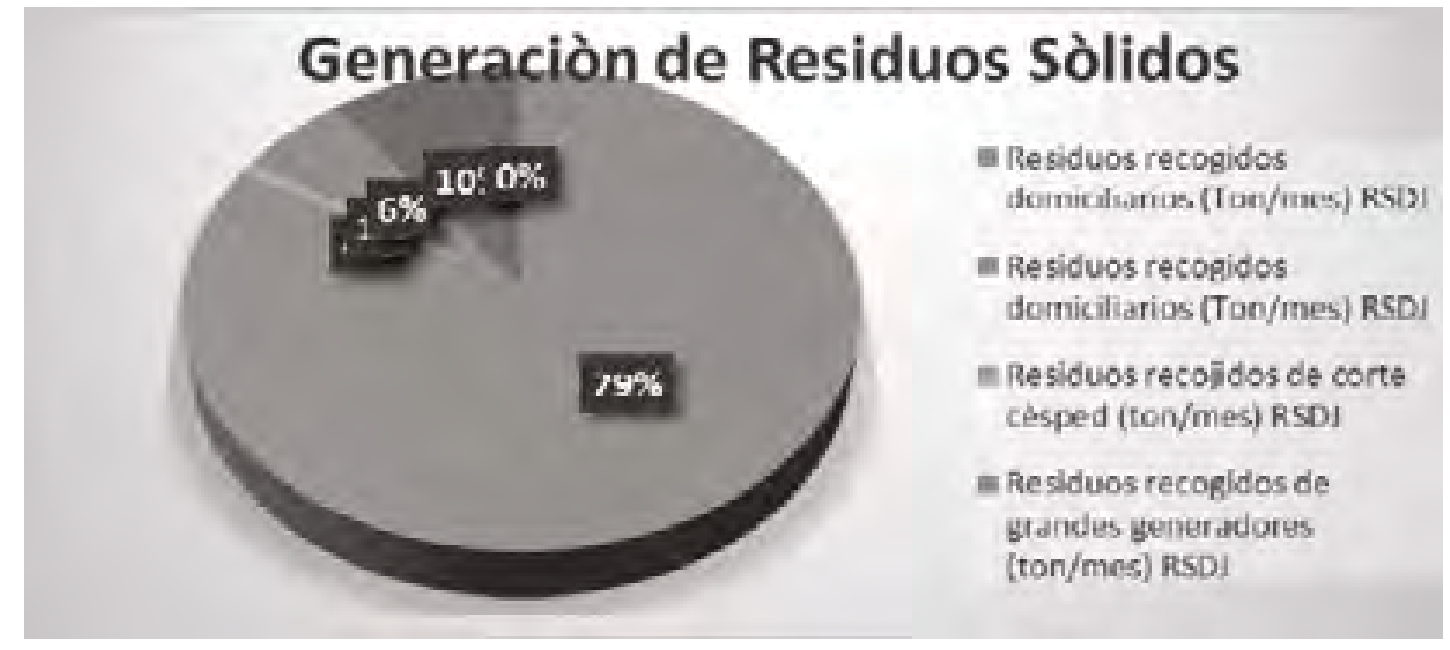

Gráfico 2. Generación de Residuos Sólidos. Fuente: Creación Propia. 
Analisis: en la tabla y grafica anterior se puede observar el promedio de las cantidades (toneladas) de residuos solidos que son producidos entre los meses de junio a diciembre del año 2015; siendo la mayor cantidad los residuos domiciliarios con un porcentaje de 79\%, (Ton/mes) RSDJ 149.167,48. (Alcalde Mayor de Bogotá, 2016)

Tabla 5 - Características de los residuos.

Caracterización de los residuos en el sitio de disposición final, de acuerdo con lo establecido en el título F del RAS, en área Urbana

\begin{tabular}{|c|c|c|}
\hline \multirow{4}{*}{ Material } & Promedio 2015 \\
\cline { 2 - 3 } & Contenido \% \\
\cline { 2 - 3 } & Cartón & $6,26 \%$ \\
\cline { 2 - 3 } pon & Caucho & $0,89 \%$ \\
\cline { 2 - 3 } por material & Cenizas & $0,17 \%$ \\
\cline { 2 - 3 } & Cerámica & $0,34 \%$ \\
\cline { 2 - 3 } & Cuero & $0,70 \%$ \\
\cline { 2 - 3 } & Hueso & $0,08 \%$ \\
\cline { 2 - 3 } & Ladrillo & $0,41 \%$ \\
\cline { 2 - 3 } & Madera & $2,58 \%$ \\
\cline { 2 - 3 } & Materia Orgánica & $42,24 \%$ \\
\cline { 2 - 3 } & Metales & $1,39 \%$ \\
\cline { 2 - 3 } & Minerales & $0,11 \%$ \\
\cline { 2 - 3 } & Otros & $1,58 \%$ \\
\cline { 2 - 3 } & Papel & $9,41 \%$ \\
\cline { 2 - 3 } & Plástico & $23,39 \%$ \\
\cline { 2 - 3 } & Textil & $8,13 \%$ \\
\cline { 2 - 3 } & Vidrio & $2,32 \%$ \\
\hline
\end{tabular}

Fuente: Fuente: CGR SA ESP - 2015. Parámetro incluido respecto a PGIRS 2015.

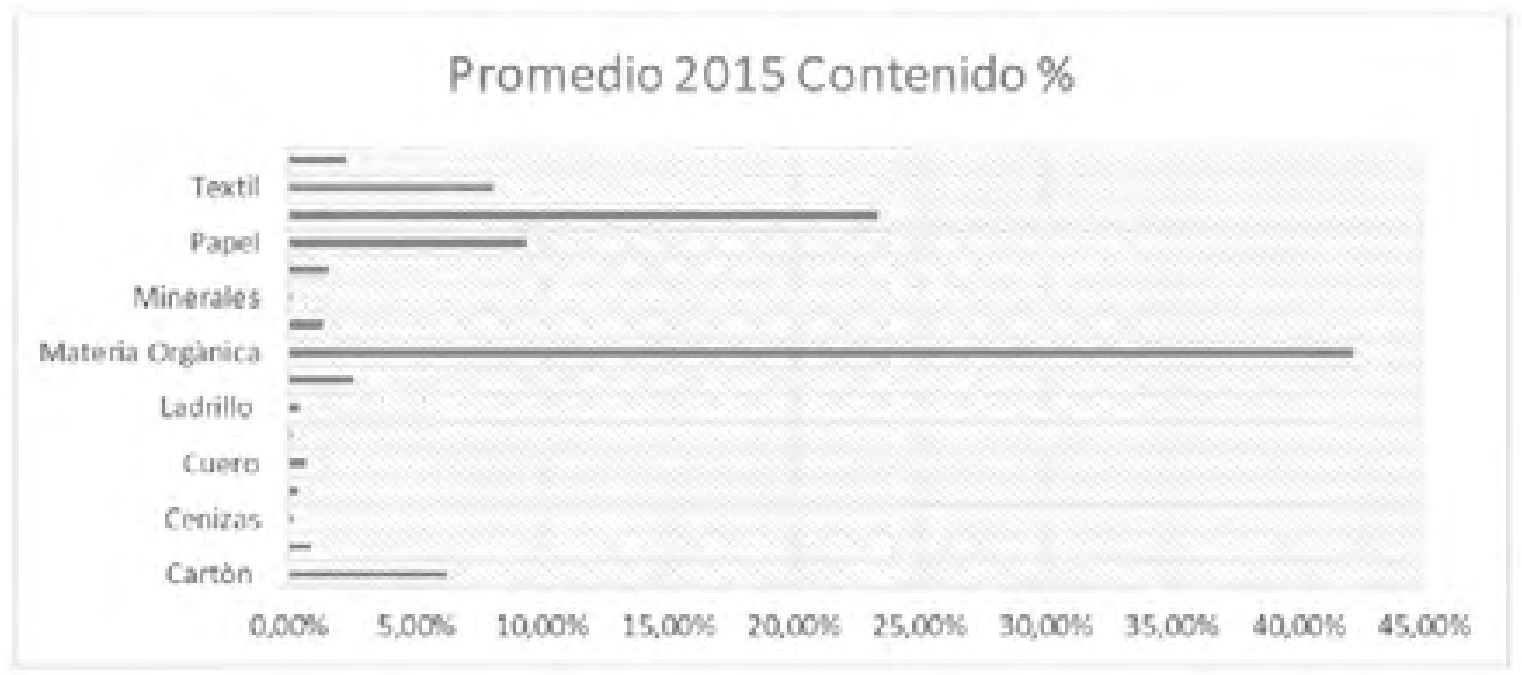

Gráfico 3. Características de los residuos. Fuente: Creación Propia. 
Analisis: En la tabla y grafica anterior se observa el promedio de los residuos en el sitio de disposición final, en donde la materia orgánica representa el porcentaje más alto con un 42,24\% y los residuos de huesos representan el más bajo con un 0,08\%. (Alcalde Mayor de Bogotá, 2016).

Tabla 6 - Corte de Césped y Árboles.

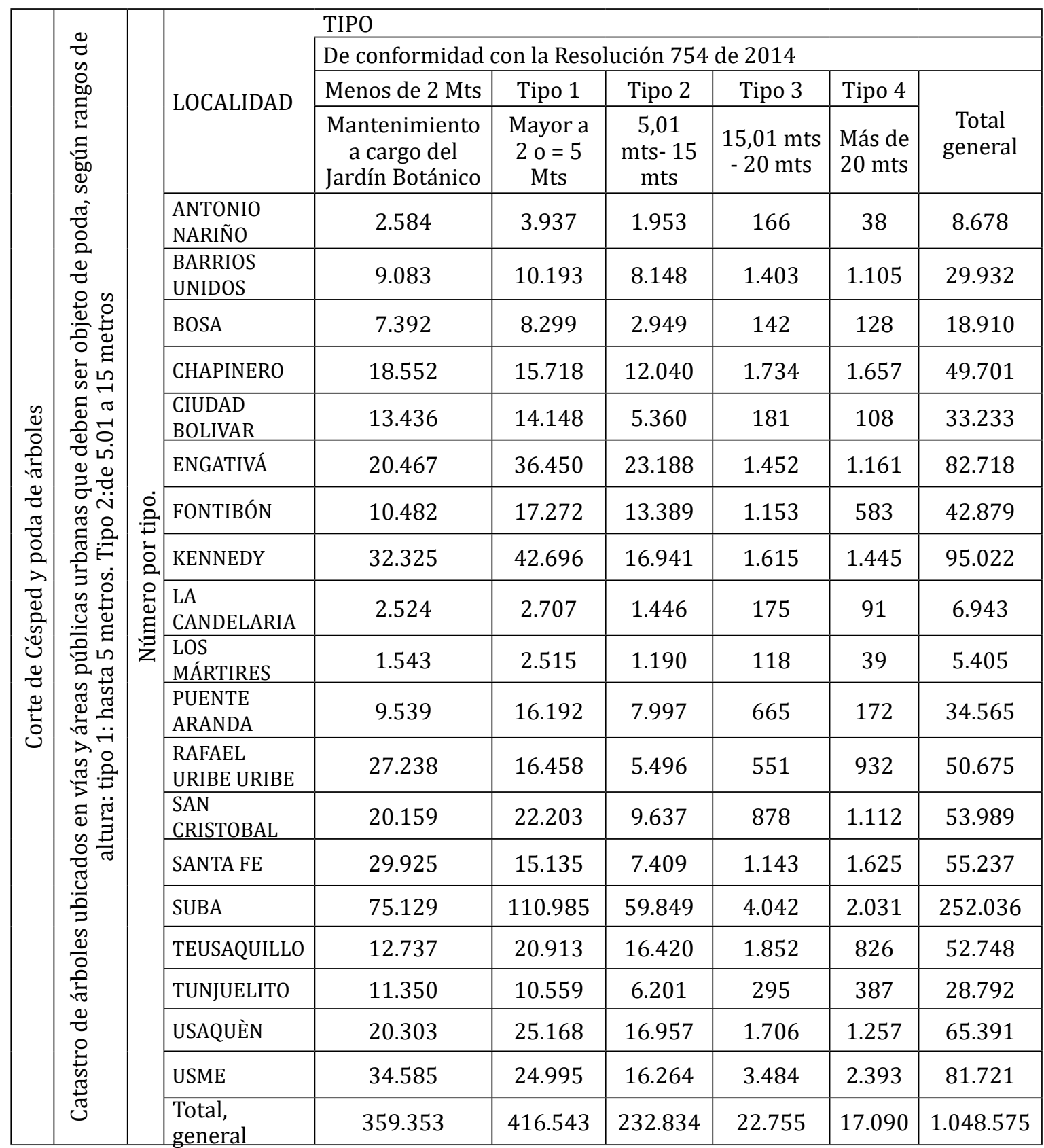

Fuente: Consulta suministrada en el Sistema de información para la Gestión del Arbolado Urbano SIGAU, abril de 2016. Memoria de reunión del 04 de mayo de 2016. Información modificada, respecto del Decreto 548 del 17 de diciembre de 2015. Información aprobada mediante Decreto 227 de 2016. 


\section{Corte de Cèsped y poda de àrboles}

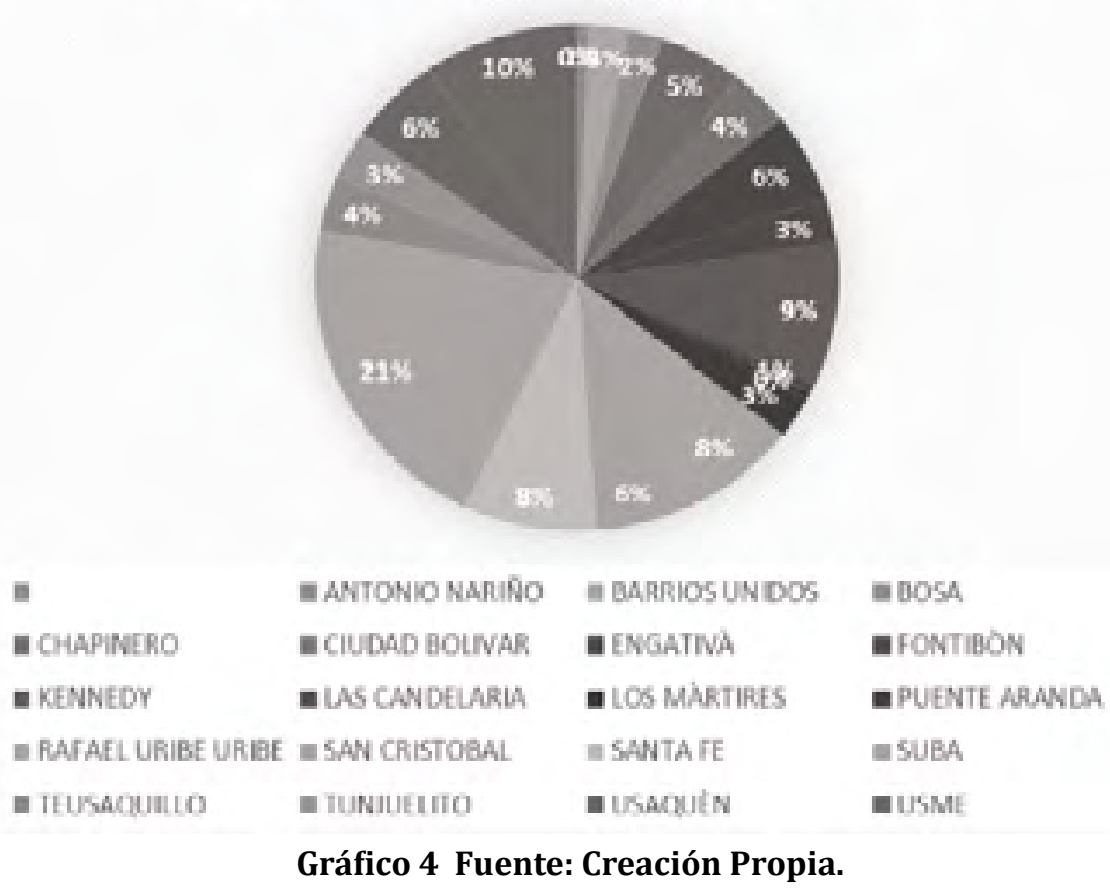

Análisis: En la tabla y grafica anterior se observa el promedio por localidades del corte de césped y poda de árboles, donde la localidad que muestra el porcentaje más alto es Suba con un 21\%, mientras que el porcentaje más bajo (3\%) lo muestran las localidades de Mártires, la Candelaria y Antonio Nariño. (Alcalde Mayor de Bogotá, 2016)

Producto de estudios técnicos, enmarcados en los PGIRS, que permitan diversas alternativas a corto, mediano y largo para la ciudad se plantean los siguientes programas: programa institucional para la prestación de servicios públicos de aseo, programa de recolección, transporte y transferencia, programa de barrido y limpieza de vías y áreas públicas, programa de corte de césped y poda de árboles, programa de lavado de áreas públicas, programa de aprovechamiento, programa de inclusión de recicladores, programa de disposición final, programa de gestión de residuos sólidos especiales, programa de gestión de residuos en área rural, programa de gestión de riesgo, todos con sus respectivos objetivos, características, metas, presupuesto financiero, seguimiento $\mathrm{y}$ control, para garantizar un efectivo resultado de los mismos. (Alcalde Mayor de Bogotá, 2016).

\section{LAS DECLARATORIAS DE EMERGENCIAS SANITARIAS Y LA PROYECCIÓN DE DESMONTAR LOS VERTEDEROS DE SÓLIDOS A CIELO ABIERTO COMO RETOS QUE DEBE ENFRENTAR COLOMBIA PARA CUMPLIR CON LOS OBJETIVOS DE DESARROLLO SOSTENIBLE (ODS)}

La investigación denota que existe un amplio bloque de regulación normativa, la cual ha venido ajustándose en el devenir del tiempo, el Decreto 620 de 2007, determinó un sistema para definir la operatividad en el tratamiento de los RS, que parte desde lo macro art. 3 o literal a) que refiere:

- Rellenos Sanitarios, las instalaciones de un relleno sanitario están definidas por la norma nacional RAS 2000 (Resolución 1096 del 17 de noviembre de 2000 del Ministerio de Ambiente, Vivienda y Desarrollo Territorial -MAVDT-), los Decretos Nacionales 838 de 2005 y 1220 de 2005 y la Ley 142 de 1994. 
- Plantas de tratamiento de lixiviados producidos en el respectivo relleno sanitario. La planta de tratamiento de lixiviados, necesariamente tratará los efluentes, producto de la operación del Relleno Sanitario.

- Plantas de tratamiento y aprovechamiento de biogás generado en el relleno sanitario. Si en el relleno sanitario no existe suelo disponible para el aprovechamiento, esta instalación podrá ser ubicada en su entorno.

- Celda de Seguridad, instalación técnica anexa al Relleno Sanitario.

- Plantas de compostaje de residuos recolectados por la entidad prestadora del servicio. Decreto 1713 de 2002 por el cual se reglamenta la Ley 142 de 1994, la Ley 632 de 2000 y la Ley 689 de 2001, en relación con la prestación del servicio público de aseo, y el Decreto Ley 2811 de 1974 y la Ley 99 de 1993 en relación con la Gestión Integral de Residuos Sólidos.

- Plantas de Incineración para residuos hospitalarios y similares. La incineración de residuos hospitalarios está regulada por las disposiciones que en la materia fije el Ministerio de Protección Social, especialmente los determinados en la Resolución No. 1096 de 2000, que adopta el Reglamento Técnico del Sector de Agua Potable y Saneamiento Básico -RAS 2000, expedida por el Ministerio de Ambiente, Vivienda y Desarrollo Territorial, la cual establece los residuos que se pueden incinerar.

- Plantas de tratamiento y manejo de residuos peligrosos. Se incluyen los residuos hospitalarios que pueden ser clasificados como peligrosos.

- $\quad$ Estaciones de Transferencia. Sus aspectos técnicos y ambientales se regulan de acuerdo a las disposiciones dadas por el RAS 2000..."

Igualmente, la norma en cita regula y desarrolla la estructura del sistema de aseo para el distrito, lo que deja ver más el afán en la recogida que un tratamiento con enfoque ambiental y de objetivos de desarrollo sostenible -6-7-8-12-15- ODS-
Así tenemos igualmente como el Decreto 456 $-2010$

TITULO II ARTICULACIÓN DE LAS POLÍTICAS, ESTRATEGIAS, PROGRAMAS Y PROYECTOS POR EJES DE ACTUACIÓN

CAPITULO 1 Objetivos por Ejes de Actuación y Políticas Artículo 24, determinó la organización de las políticas, estrategias, programas y proyectos por ejes de actuación. Las políticas, estrategias, programas y proyectos del PMIRS se articulan en torno a 3 ejes de actuación con el fin de señalar objetivos integrales por cada eje y las metas de corto, mediano y largo plazo para cada uno de los indicadores de seguimiento y control de la ejecución del plan. El plan se estructura en los siguientes ejes:

1. Eje Territorial-Ambiental

2. Eje Social-Productivo

3. Eje Económico-Financiero

Se procura señalar que existe una política pública de corte transversal aunque la realidad denota que ello sigue siendo un aspecto que solo se queda en proyectos, pues las problemáticas del vertedero Doña Juana, las concesiones a particulares -operadores-, no generan una responsabilidad que procure la transición a verdaderos cambios y así se dejen de usar los vertederos como una única solución (la cual lleva más de dos siglos dándose a gran escala) al problema de los residuos. Estos aspectos se pueden validar en el simulador http://oab. ambientebogota.gov.co/comparar indicadores. php, el cual permite aplicar diversas variables del tonelaje depositados en el vertedero y los tratamientos a la antigua.

En septiembre de 2017 se cumplieron 2 años de la aprobación de los objetivos de desarrollo sostenible (ODS); estos constituyen la columna vertebral y aglutinan los retos del desarrollo ya que son propicios para que las empresas privadas orienten su trabajo en función de los mismos. (ODS, Año 2 Analisis, tendencias y liderazgo empresarial en España.) 


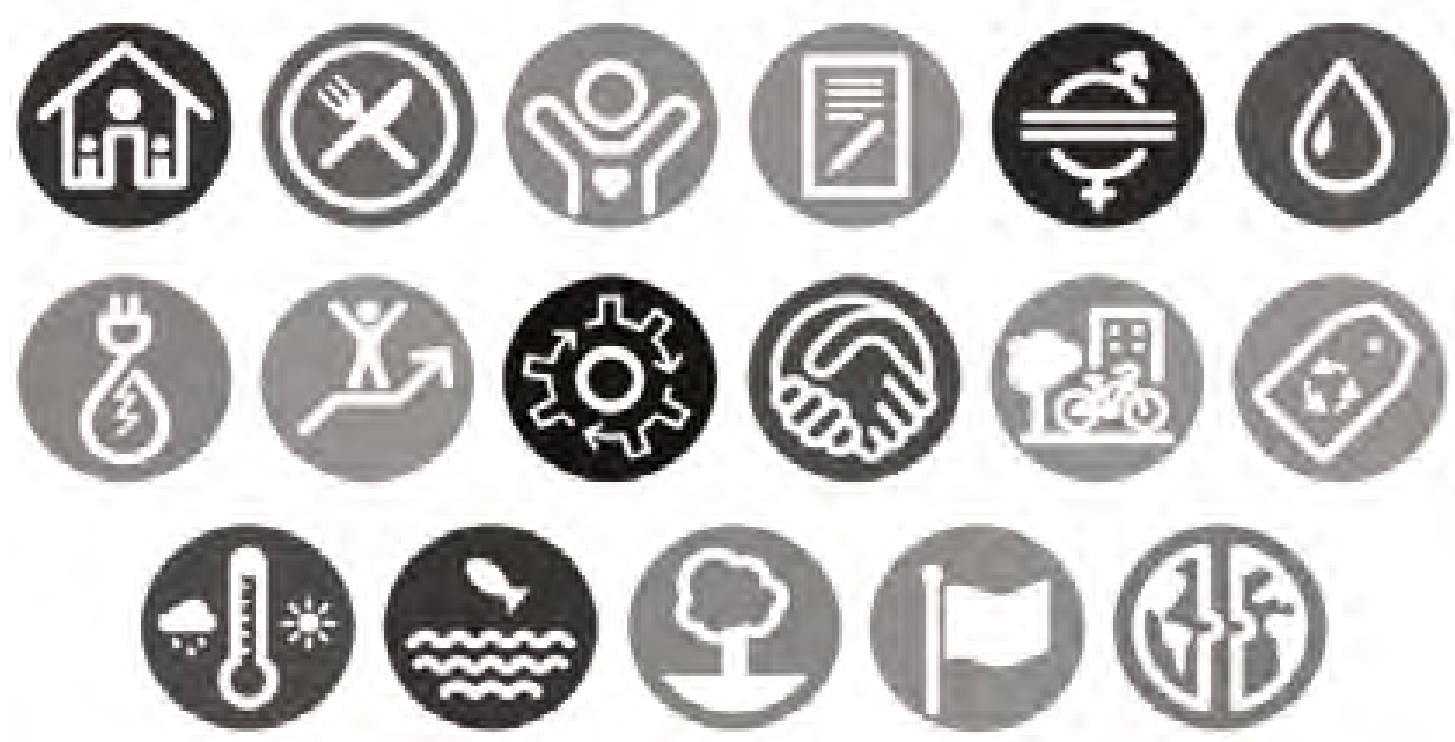

Gráfico 8 Tomada: https://www.un.org/sustainabledevelopment/es/objetivos-de-desarrollo-sostenible/

Colombia identificó las metas para el cumplimiento de los ODS, adoptada en 193 países; el proyecto trata de 16 grandes apuestas previstas en el documento CONPES 3918, para cumplir con las 169 metas ODS debe designar 30 entidades nacionales para que lideren las acciones hasta el 2030, marcando rutas de desarrollo social y económico para favorecer al medio ambiente. (Departamento Nacional de Planeación, 2018).

La gran mayoría de los países se comprometieron con los ODS, pero Colombia ha sido el primer país en definir las acciones concretas para la implementación de la mencionada agenda; incluyó las metas de la ODS en el Plan Nacional de Desarrollo y con la aprobación de CONPES, direccionará todos los esfuerzos del gobierno para hacer cumplir las metas. (Departamento Nacional de Planeación, 2018).

Colombia es el primer país comprometido con la Agenda 2030; el Plan Nacional de Desarrollo (PND), el cual incluye más de la mitad de las 135 metas de los ODS; por otra parte, se encuentra representado por la Asociación de Fundaciones Familiares y Empresariales AFE y las 71 fundaciones asociadas por ser un aliado importante para el gobierno y las organizaciones internacionales con base a las metas de los ODS.
(AFE Asociación de Fundaciones Familiares y Empresariales, s.f.).

El DPN identificó 6 desafíos estratégicos para poder implementar en los ODS, la AFE $\mathrm{y}$ sus fundaciones colaboran con los desafíos estratégicos, para que también logren convertir los ODS en un idioma universal para el desarrollo, también pretenden crear nuevas alianzas con el sector público y privado. (AFE Asociación de Fundaciones Familiares y Empresariales, s.f.).

La AFE y sus fundaciones colaboran en desafíos estratégicos asumiendo propósitos de lograr convertir los ODS y sus metas en el mundo fundacional en Colombia y crea nuevas alianzas con el sector público y privado. (AFE Asociación de Fundaciones Familiares y Empresariales, s.f.).

Así mismo, con respecto a la protección de mares colombianos de la contaminación, teniendo en cuenta las diferentes investigaciones, más de 8 millones de toneladas de basura terminan cada año recorriendo las aguas del mundo, lo que perjudica los ecosistemas marinos. En noviembre del 2017 fue creado un fondo de 5 millones de dólares, los cuales ayuda a conservar la biodiversidad en las zonas protegidas del pacifico colombiano. (Colprensa, 2018). 
Con una inversión de 57 millones de dólares, se está desarrollando el programa de conexión Biocaribe, el cual fue implementado por la Organización de las Naciones Unidas para la Alimentación y la Agricultura. (Colprensa, 2018).

El principal problema de contaminación de los océanos tiene que ver con todos aquellos desechos de materias orgánicas y nutrientes, la contaminación microbiana, residuos sólidos, elementos químicos, metales pesados, residuos oleosos, y derrames de petróleos. (Colprensa, 2018).

La Armada Nacional, en uno de sus estudios, señaló que el $80 \%$ de los desperdicios que se arrastran al mar son arrojados desde la orilla por la población, y el $20 \%$ proviene de embarcaciones y el $60 \%$ de los desechos están compuestos de plásticos. (Colprensa, 2018).

\section{Ausencia de políticas Distritales con enfoque ODS-2030}

La relevancia de la investigación nos lleva a contrastar que en la actualidad el Distrito de Bogotá por medio de la Secretaria Ambiental, si bien tiene trazadas algunas políticas ambientales (http:// www.ambientebogota.gov.co/web/sda/politicasambientales, recuperado julio de 2018), No aparecen en ella de manera clara y reglamentada una política pública con enfoque ODS.

Así tenemos que de todas las políticas si bien tratan de abordar y proponer la protección en asuntos ambientales, incluso algunas están en construcción como las políticas de producción sostenible y ecourbanismos y construcción sostenibles, requiere la concurrencia de todos los actores sociales lo cual implica que los resultados están aún en construcción, lo cual como se dejó expuesto con el plan de desarrollo vigente, no porque se citen algunos ODS, ya se tiene por cumplido el reto más en asuntos de contaminación con los actuales usos de los vertederos que datan del siglo XIX.

\section{CONCLUSIONES}

El distrito de Bogotá a la fecha - 2018- no ha implementado una política con enfoque ODS-2030, que permita desarrollar dichos compromisos de Estado en temas ambientales en especial los previstos en los objetivos de desarrollo sostenible 6-7-8-12-15- ODS-

Los sistemas actuales de tratamiento de residuos sólidos del distrito no tienen un plan de transición de vertederos -rellenos- a cielo abierto a centrales de optimización a energías limpias derivadas de los RS

Es importante replantear las actuales normatividades en contratación, concesión y aplicación de cláusulas -reversión-, a fin de asegurar los recursos públicos en beneficio de la sociedad residente en el distrito, que vincule tales deberes de los operadores en el contrato de concesión, como tal.

Se requiere un debate en el legislativo a nivel nacional a fin reformar el sistema contractual en el sector de servicios públicos de aseo, con el fin de incluir en futuras concesiones de manera contractual y especifica el cambio o migración de los operadores para insertar tecnologías ambientales y plantas reales de tratamiento y cierre de los vertederos actuales, so pena de no continuidad en dicho sector.

Es necesario fortalecer una pedagogía con enfoque ODS para fomentar y liderar talleres, diplomados, congresos, entre otros, ya que será una acción en pro de la formación de todos los actores públicos - privados, que con la vinculación transversal de la comunidad se logrará la búsqueda de una nueva cultural de manejo en los residuos sólidos con un real respeto por los derechos ambientales 


\section{BIBLIOGRAFÍA}

- Agencia de Cooperación Internacional del Japón (JICA) y Unidad Administrativa Especial de Servicios Públicos (UAESP). (2013). Proyecto de Estudio del Plan Maestro para el Manejo Integral de Residuos Sólidos en Bogotá D.C. Kokusai Kogyo Co. LTD - Ex Research Institute LTD., Bogotá. Recuperado de: http://www. uaesp.gov.co/Uaesp_jo/images/SubdRBL/ jica/GEJR13213_BOGOTA_RESUMEN.pdf

- Alcalde Mayor de Bogotá. (2016). Documento Tecnico de Soporte Plan de Gestión Integral de Residuos Sólidos para Bogotá. Alcaldia Mayor de Bogotá, Documento Tècnico de Soporte, Bogotá. Recuperado de: Alcaldia de Bogotá . (s.f.). Unidad administrativa especial de servicios públicos. Obtenido de UAESP: Recuperado de: http://www.uaesp.gov.co/ index.php/aseo-uaesp/aprovechamiento/ contenedores-aprovechamiento

- Alcaldia de Bogotá y Secretaria Distrital de Hábitat. (s.f.). Guìa tècnica para el aprovechamiento de residuos orgánicos a través de metodologìas de compostaje y lombricultura. Guìa Tecnica, Bogotá. Recuperado de: http://www.uaesp.gov.co/ images/Guia-UAESP_SR.pdf

- Alcaldia Mayor de Bogotá. (2018). Resultados generales para las estrategias de Educación. Bogotá. Recuperado de: http:// www.uaesp.gov.co/images/Resultados_ estrategias_educacion_ambiental.pdf

- Castro B, F. (2014). Caracterización de la población recicladora de oficio en Bogotá. Unidad Administrativa Especial de Servicios Públicos, Bogotá. Recuperado de: http:// www.uaesp.gov.co/images/InformeCaracter izacionpoblacinrecicladoradeoficio_2014.pdf

- Código Sanitario Nacional, Articulo 65.

- Decreto 891 de 2002 (Presidencia de la República 7 de mayo de 2002).
- Gaceta Oficial Digital de la República de Panamá, № 25821, CONTRATO DE OPERACIÓN DEL SERVICIO PÚBLICO DE ASEO EN SUS COMPONENTES DE BARRIDO DE CALLES Y ÁREAS PÚBLICAS, RECOLECCIÓN, TRANSPORTE, Y DISPOSICIÓN FINAL DE RESIDUOS SÓLIDOS EN RELLENO SANITARIO, martes 26 de junio de 2007

- Juzgado Tercero Administrativo Circuito de Bogotá Sección Primera., 11001-3334-0032012-00131-00 y 11001-3334-004-201300054-00 (Juzgado Tercero Administrativo 12 de febrero de 2014).

- Ley № 80. Articulo 19. Congreso de la República 28 de octubre de 1993.

- Medina, A. (2015). La reversion en el contrato de concesión del servicio público de aseo. Ed. U. Externado.

- Peñalosa, E. (2016). Proyecto del Plan de Desarrollo Bogotá 20162020. Proyecto Bogotá. Recuperado de: Periodico REDODS-2030.(2018). edicion 1 y 2 ISSN 2539-2778. Editorial Reducared, 2017-2018 Recuperado de: https://repository.unad.edu.co/ bitstream/10596/3417/1/79911240.pdf

- Sala de lo Contencioso Administrativo Sección Tercera, 11001-03-26-000-20020045-01 (Consejo de Estado 27 de octubre de 2005 ).

- Secretaria Distrital del medio ambiente. (2018). Recuperado de: http://www. ambientebogota.gov.co/web/sda/ politicas-ambientales

- Corte Constitucional. (1996). Sentencia C-250/96. Proceso № D-1064

- Corte Constitucional. (2012).Sentencia C-300/12. Expediente D-8699

- Tribunal de Arbitramiento de Consorcio Aseo S.A. E.S.P, Laudo Arbitral (Tribunal de Arbitramiento de Consorcio 30 de marzo de 2016). 